\title{
ANALYSIS OF EMPLOYMENT IN THE MANUFACTURING SECTORS \\ OF NINE URBAN AREAS: THE RELATION BETWEEN
}

AVERAGE HOURS WORKED AND EMPLOYMENT

\author{
by
}

George Christopher Kottis*

International Bank for Reconstruction and Development

Summary

This paper investigates the short-term relationship between changes in the average number of hours worked and the number of workers employed. Nine medium-sized urban areas in Michigan have been chosen for the study, which deals with production workers engaged in manufacturing.

It is assumed that changes in external demand for manufactured goods directly effect the amount of labor used by the manufacturing sector of the nine areas. An increase in demand causes an increase in labor, while a decrease in demand has a negative effect on labor. Firms may adjust either the number of hours worked by their production workers or the number of workers they employ, or both. Correlation analysis is used to investigate the existence of leads or lags in the relationship between the two variables. A distributed-lag regression function is employed to examine the quantitative importance of this relationship.

The results of correlation suggest a tendancy for the two aggregate variables to change simultaneously or with short time lags. The time pattern of the relationship depends on a number of factors, the most important of which are discussed in the paper. The results of regression indicate that the strength of the quantitative relationship can vary from area to area when the relationship between employment and hours worked during the same period is considered, while no significant regional differences are observed in the strength of the relationship between employment and hours worked in previous periods. Some policy implications of the results are discussed at the end of the paper.

\section{Introduction}

This study attempts to investigate the short term relationship between average weekly hours and employment in the manufacturing sectors of a number of urban areas. It examines (a) the relation between these two variables, particularly with respect to the time factor involved and (b) the possibility of predicting changes in the labor markets of these areas by monitoring changes in the length of the manufacturing workweek.

Perhaps the first attempt to test this relationship at the local level, it is not the first to deal with the overall problem. In the last two decades a number of economists interested in cyclical changes have concerned themselves with fluctuations in the average number of weekly hours worked in various sectors of the national economy. 1 Such fluctuations are often employed as an important indicator of the demand for manufacturing workers and are used to predict the state of various other economic variables. 2

In the past, interest has been focused on the relationship either at the industry level or at the aggregate national level. However, because of the heterogeneity of conditions prevailing in different urban areas, the national averages may conceal significant regional differences. This study

* The work presented in this paper is based on a $\mathrm{Ph} . \mathrm{D}$. dissertation written at Wayne State University under the supervision of Dr. Wilbur R. Thompson. The author wishes to express his thanks for the very constructive comments of Professor Wilbur R. Thompson, John M. Mattila and Howard Bourne. Two unknown referees made usggestions which led to a significant improvement of the manuscript. Part of the research was financed by the Resources for the Future, whose assistance is gratefully acknowledged. 
attempts to fill the gap by using data for nine medium-sized urban areas in an effort to find out whether there are any significant regional patterns or anomalies especially with regard to any time lags involved. Better understanding of the relationship may be particularly useful in predicting short-run changes in manufacturing employment and also in providing an indication of future surpluses or shortages in the labor market.

Section 2 of the paper contains a theoretical discussion of the relationship; section 3 describes the methodology and data used; section 4 presents the results of the analysis, and sectinn 5 includes a summary and conclusions.

\section{The Hypothetical Relationship}

Because the largest part of the manufactured goods produced in these areas are exported to other areas, manufacturing production in the nine urban areas of the sample fluctuates primarily as a result of changes in external demand. 3 Generally speaking, changes in the demand for locally produced goods can be due to fluctuations in the overall level of the national economy, to variations in national (or international) demand for the products in question, or to changes in the competitive position of the manufacturing industries of the areas under consideration relative to similar activities elsewhere. Changes in the level of local manufacturing output can be expected to directly affect variations in the amounts of inputs used to produce that output. ${ }^{4}$ Substitution of one input for another is possible but it is assumed that it cannot be so extensive as to cause an inverse relationship, such that a decrease in the amount of the input used follows an increase in its output, at least in the short run. 5

This paper focuses on only one input: labor. When the demand for the output of the manufacturing sector changes, manufacturing firms can be expected to alter the amount of labor they use, possibly with some time lag. This can be done in one of the following ways: they can adjust the number of hours worked by their employees; they can adjust the number of workers they employ; or they can choose a combination of the two alternatives.

A number of economists have suggested that the demand for manufactures affects firstly the length of the individual workweek, influencing the number of workers later. There are plausible theoretical reasons for this. (a) The firm may be reluctant to adjust the number of workers if it is not certain that the new conditions of demand will persist. Disruption of a trained work force and the creation of a moral problem may result from premature layoffs, while the expense of recruiting and training new workers may be wasted in a short-term expansion. Increasing or decreasing the hours of work offers a method of adjusting the labor input. It is also a more flexible method responding rapidly while allowing the firm to economize on the use of its trained supervisory and administrative staff. (b) Given a tight labor market the firm may have no alternative but to increase the number of work hours when faced with the hiring of unqualified workers. (c) Even when the state of the labor market is not one of general shortage; certain firms may experience employment bottlenecks that do not allow them to find the additional trained workers they need. 6

Against the above consideration one must weigh such factors as the additional cost of premium wage rates for overtime work and the excessive pressures that overtime work puts on manpower and equipment. ${ }^{7}$ Nevertheless there seems to be general consensus that the argument in support of adjustments in the length of the workweek is stronger. Thus, one could expect firm managers to try to shorten the workweek before resorting to job cuts during periods of recession, while in periods of expansion they will choose to lengthen the workweek before hiring additional workers. In other words, changes in thw workweek of production workers are usually expected to precede employment adjustments in both phases of the business cycle. ${ }^{8}$

The U. S. National Bureau of Economic Research has estimated that changes, in the United States, in workhours during business cycles have shown a median lead of six months at the peak and four months at the trough since 1921.9 However, that analysis is based on aggregate data which conceals significant variations in the behavior of different industries and even of different plants.10 The employment policies of firms in response 
to changes in the demand for their products may vary according to the industry that a firm belongs to. Some of the factors that may influence employment practices are the degree of organization of the relevant labor market, the policies of the respective trade unions, the level of labor skills needed, and a number of other less important characteristics uniquely associated with particular industries or fims.11 In view of these factors, local economies may demonstrate very diverse patterns depending upon their particular industry mixes.

As explained in the following section this paper uses aggregative time series, the data covering a large number of heterogeneous firms, in a number of different industries. One must then expect some differences in behavior among the manufacturing sectors of each of the nine areas under examination. But, in view of the fact that the cities in question were deliberately chosen for essential similarity, the paper attempts to examine the possibility of establishing any general relationships between changes in the number of hours worked and changes in the number of manufacturing workers, despite shortcomings created by the aggregate character of the data.

\section{Methodology}

The nine urban areas examined in the paper are the following: Battle Creek, Benton Harbor, Flint, Grand Rapids, Jackson, Kalamazoo, Lansing, Muskegon, and Sagniaw. In 1965 the population of these SMSA's ranged from 137,000 for Jackson to 500,000 for Grand Rapids. A11 areas are in the state of Michigan and their economies are based primarily on manufacturing production, with the possible exception of Lansing which is also a major center for government and educational services. Furthermore, most areas specialize in the production of durable goods, although the degree of dependence varies from area to area, often significantly.

As mentioned earlier, the paper deliberately focuses its attention on urban areas such as these that do not presont any striking economic differences, introducing a suitable degree of control in the relation between the two variables. 12 Another study might examine an economically diverse group of cities in order to test whether size or other differences have any effect on the relation in question.

The econometric part of the paper is based on two time series for each of the nine areas of the study: Manufacturing Employment (ME) and Average Hours Worked by Supervisory Personnel (AHWM), each of the series consisting of 216 monthly observations. 13 The series were deseasonalized to eliminate the effect of short-term, repetitive, and therefore predictable changes. 14 At the aggregate leve1, there is no evidence of an upward or downward trend in the workweek worked by manufacturing workers unlike the nonmanufacturing sector which shows a strong downward trend.15 From the deseasonalized series new ones were constructed in which the absolute values of the seasonally adjusted monthly observations were replaced by the first differences of the same values. In order to detect any leads or lags in the relation between the two variables the independent variable was lagged up to eighteen times. 16 This made possible the correlation of changes in one variable in one time period with changes in the other variable in previous periods.

Simple correlations were performed between the change in one period and the change in the Average Hours Worked by Non-supervisory Personnel in the same time period, as well as in each one of the previous eighteen monthly periods. From the table of the correlation coefficients it became apparent that in most areas under consideration changes in manufacturing employment in one time period were related to changes in the average hours worked in manufacturing in the same as well as in a number of previous periods. The relationship seemed to seaken as the time lag increased. This served as a guide for formulating the regression equation which was assumed to be of the following form:

$$
\text { (1) } Y_{t}=\beta_{0}=\beta_{1} X_{t}+\beta_{2} X_{t-1}+\beta_{3} X_{t-2}+\ldots \ldots \ldots \ldots+\varepsilon_{t}
$$

where $\mathrm{Y}$ symbolizes the change in manufacturing employment and $\mathrm{X}$ stands for the change in the average number of hours worked in the manufacturing sec- 
tor. In order to sidestep the problem of multicollinearity ${ }^{17}$ the above function was transformed into a KOYCK function for distributed lags. This was done by assuming $\beta_{t}=\delta j_{t-j}$, where $\delta<1$ and $j=1,2,3, \ldots$ This condition implies that the peak of the effect of $X$ on $Y$ is felt at the same time period after which there is a steady decline in its importance. As explained in section 4, this assumption was realistic only in part. By lagging equation (1) one period, multiplying through by $\delta$, subtracting the new equation from equation (1) and finally moving the term $\delta y_{t-1}$ to the right-hand side, equation (2) is obtained: 18

(2) $Y_{t}=\beta_{0}(1-\delta)+\beta_{1} X_{t}+\delta Y_{t-1}+\left(\varepsilon_{t}-\delta \varepsilon_{t-1}\right)$

\section{The Empirical Results}

The correlation analysis reveals a rather well-defined association between the variation of changes in average hours worked in manufacturing $(\triangle A H W M)$ and changes in manufacturing employment $(\triangle M E)$. The coefficients of correlation appear in Table 1.19

Table 1

Coefficients of simple correlations of Changes in Average Hours Worked in Manufacturing $(\triangle \mathrm{AHWM})$ with Changes in Manufacturing Employment $(\triangle \mathrm{ME})$.

\begin{tabular}{|c|c|c|c|c|c|c|c|}
\hline City & & $\mathrm{AHWM}$, & $\triangle \mathrm{AHWM}_{\mathrm{t}} \mathrm{t}-1$ & $\underline{\mathrm{AHWM}}_{\mathrm{t}-2}$ & $\triangle \mathrm{AHWM}-\mathrm{t}-3$ & $\underline{\triangle A H W M}-t-4$ & Critical $\mathrm{r}^{*}$ \\
\hline Battle Creek & $\Delta M E_{t}$ & .55 & .50 & .37 & .20 & .04 & .13 \\
\hline Benton Harbor & $\Delta M E_{t}$ & .08 & .46 & .30 & .28 & .25 & .13 \\
\hline F1int & $\Delta M E_{t}$ & .69 & .35 & -.03 & .01 & .00 & .13 \\
\hline Grand Rapids & $\Delta \mathrm{ME}_{\mathrm{t}}$ & .90 & .33 & .20 & -.01 & .02 & .13 \\
\hline Jackson & $\Delta \mathrm{ME}_{\mathrm{t}}$ & .82 & .38 & .11 & .01 & .05 & .13 \\
\hline Kalamazoo & $\Delta M E_{t}$ & -.02 & .03 & .01 & -.00 & .04 & .13 \\
\hline Lansing & $\Delta \mathrm{ME}_{\mathrm{t}}$ & .73 & .36 & -.07 & .03 & .00 & .13 \\
\hline Muskegon & $\Delta \mathrm{ME}_{\mathrm{t}}$ & .68 & .27 & .04 & -.04 & -.03 & .13 \\
\hline Saginaw & $\Delta M E_{t}$ & .30 & .18 & .14 & .13 & .07 & .13 \\
\hline
\end{tabular}

*at the five percent level of significance.

In seven of the nine urban areas the coefficients are strongest when no time lag is involved, suggesting a nearly simultaneous change in both variables. The coefficients decrease in importance when time lags are introduced. In certain cases the decrease is very gradual (e.g. Battle Creek) while in others it is more abrupt (Flint, Grand Rapids). In one of the other two areas (Benton Harbor) there is no evidence of simultaneous association; the only statistically significant coefficients appear when time lags of one or more months are introduced. Kalamazoo is the only center for which there is no evidence on any association in the variation of the two variables, probably due to the relatively different industry mix of this city. Unlike the other eight areas (which specialize more or less in the production of durable goods) Kalamazoo depends also heavily on nondurable products. The demand for nondurable goods fluctuates much less than the demand for durables and is more predictable. For this reason the average weekly hours (as well as the average weekly overtime hours) fluctuates significantly less than in the durable goods sector and demonstrates different time patterns. 
It was observed that the relationship between changes in the average hours worked and changes in employment was stronger in areas of greater concentration in the durable good industries. The explanation for this is that different time patterns and intensity of fluctuations in the durable and non-durable goods industries are likely to weaken (or even conceal, as in the case of Kalamazoo) the relationship in areas whose economies depend upon both types of industries. 20

Excepting Benton Harbor, the relationship between average hours worked and employment is stronger when no time lags are used. This seems to contradict the hypothesis that firms may adjust the length of the workweek before they change the number of workers. An explanation may be that changes in the demand for the goods of different industries occur at different points in time during the cycle; thus, each industry may subsequently follow a different employment policy. The use of aggregate data covering a large number of industries may conceal such lags, erroneously giving the impression that the two variables expand to contract simultaneously.21 Another possibility, of course, is that contrary to what has been found for the national economy as a whole, employers in some cases simultaneously adjust the number of hours worked and the number of workers after a change in the demand for their products. 22 Benton Harbor is the only area with statistically significant results, indicating that there is no evidence of simultaneity. The correlation coefficients for this area suggest that changes in manufacturing employment take place one or more months after similar changes in the number of hours worked.

In general, the regression analysis produced rather satisfactory results. As explained in section 3, the regression equations were based on a distributed-lag transformation to by-pass the problem of multicollinearity. A function of that type relies on certain assumptions about the behavior of the regression coefficients over time, the most important of which is, that those coefficients decrease constantly as the number of periods of the time lag increases. From the table of coefficients of correlation (table 1) it becomes apparent that the relation between the two variables examined in the paper conforms to the above assumption, although somewhat imperfectly. The coefficients in table 1 suggest that the association between dependent and independent variables is usually stronger when there is no time 1 ag and weakens with the size of the lag. However, the degree of association does not decrease in exact proportion to the number of months included in the time lag, but is rather irregular and varies according to the area under consideration. This perhaps accounts for the relative success of the distributed-lag function in explaining the relation between the variables in some areas and the rather poor fit obtained in others.

The results of the regression analysis are presented in table $2 .{ }^{23}$ The figures suggest that a change in the average number of hours worked in manufacturing $(\triangle \mathrm{AHWM})$ is likely to initiate a change in manufacturing employment $(\triangle M E)$ in all but two of the areas under consideration. The regression coefficient $\left(b_{1}\right)$ in one area (Flint) is almost nine times greater than the same coefficient in another area (Muskegon), while in the remaining five areas the differences are much less pronounced. The differences in the size of regression ceofficients for various areas may be due to such factors as differences in the industry-mix of those areas, different absolute size of the various manufacturing sectors, differences in the degree of organization of the respective labor markets, and a number of other factors, some of which were idscussed in preceding parts of the paper. In order to remove the effect of the absolute size of the manufacturing sector in the various areas, the regression coefficients were weighed by the number of manufacturing workers in each area and the adjusted coefficients appear in table 3.24 It is evident from the table that the differences in the regression coefficients decrease considerably but do not disappear. The persisting differences are probably due to some of the other factors mentioned above. 25

The percentage of the variation explained by the regression varies considerably from one area to the other. It is highest. in Grand Rapids (.90) and lowest in Saginaw (.39), while in Kalamazoo and Benton Harbor the regressions are not significant statistically. The results for Kalamazoo were anticipated in view of the unsatisfactory results of correlation analysis for the same area, attributed to specialization in non-durable goods. 


\section{Table 2}

Regression of Changes in Manufacturing Employment ( $\triangle M E$ ) on Changes in Average Hours Worked in Manufacturing ( $\triangle \mathrm{AHWM}$ )*

(Standard Errors in Parentheses)

Period of Fit: 1951-68 (monthly data)

Method of Estimation: Linear

\begin{tabular}{|c|c|c|c|c|c|}
\hline \multirow{2}{*}{ City } & \multirow{2}{*}{$b_{0}$} & $\triangle \mathrm{AHWM}_{\mathrm{t}}$ & & \multirow{2}{*}{$($ per cent) } & \multirow{2}{*}{$\begin{array}{l}\text { Degrees } \\
\text { of } \\
\text { Freedom }\end{array}$} \\
\hline & & $\mathrm{b}_{1}$ & $\delta$ & & \\
\hline \multirow[t]{2}{*}{ Battle Creek } & $\Delta \mathrm{ME}_{\mathrm{t}}=192.059$ & 380,218 & 0.223 & 61.0 & 212 \\
\hline & & $(75.096)$ & $(0.019)$ & & \\
\hline \multirow[t]{2}{*}{ Flint } & $\Delta \mathrm{ME}_{\mathrm{t}}=135.206$ & $1,639.596$ & 0.379 & 55.0 & 212 \\
\hline & & $(170.877)$ & $(0.046)$ & & \\
\hline \multirow[t]{2}{*}{ Grand Rapids } & $\Delta \mathrm{ME}_{\mathrm{t}}=-450.933$ & 600.526 & 0.229 & 90.0 & 212 \\
\hline & & $(161.503)$ & $(0.029)$ & & \\
\hline \multirow[t]{2}{*}{ Jackson } & $\Delta \mathrm{ME}_{\mathrm{t}}=234.970$ & 397.836 & 0.242 & 70.0 & 212 \\
\hline & & $(86.043)$ & $(0.034)$ & & \\
\hline \multirow[t]{2}{*}{ Lansing } & $\Delta \mathrm{ME}_{\mathrm{t}}=195.748$ & 365.109 & 0.262 & 58.0 & 212 \\
\hline & & $(72.944)$ & $(0.014)$ & & \\
\hline \multirow[t]{2}{*}{ Muskegon } & $\Delta \mathrm{ME}_{\mathrm{t}}=897.814$ & 178.596 & 0.124 & 48.0 & 212 \\
\hline & & $(35.538)$ & $(0.011)$ & & \\
\hline \multirow[t]{2}{*}{ Saginaw } & $\Delta \mathrm{ME}_{\mathrm{t}}=62.510$ & 295.574 & 0.247 & 39.0 & 212 \\
\hline & & $(75.773)$ & $(0.047)$ & & \\
\hline
\end{tabular}

* Only the regressions that were statistically significant appear in the Table. 
Unweighted Compared to

Weighted Regression Coefficients

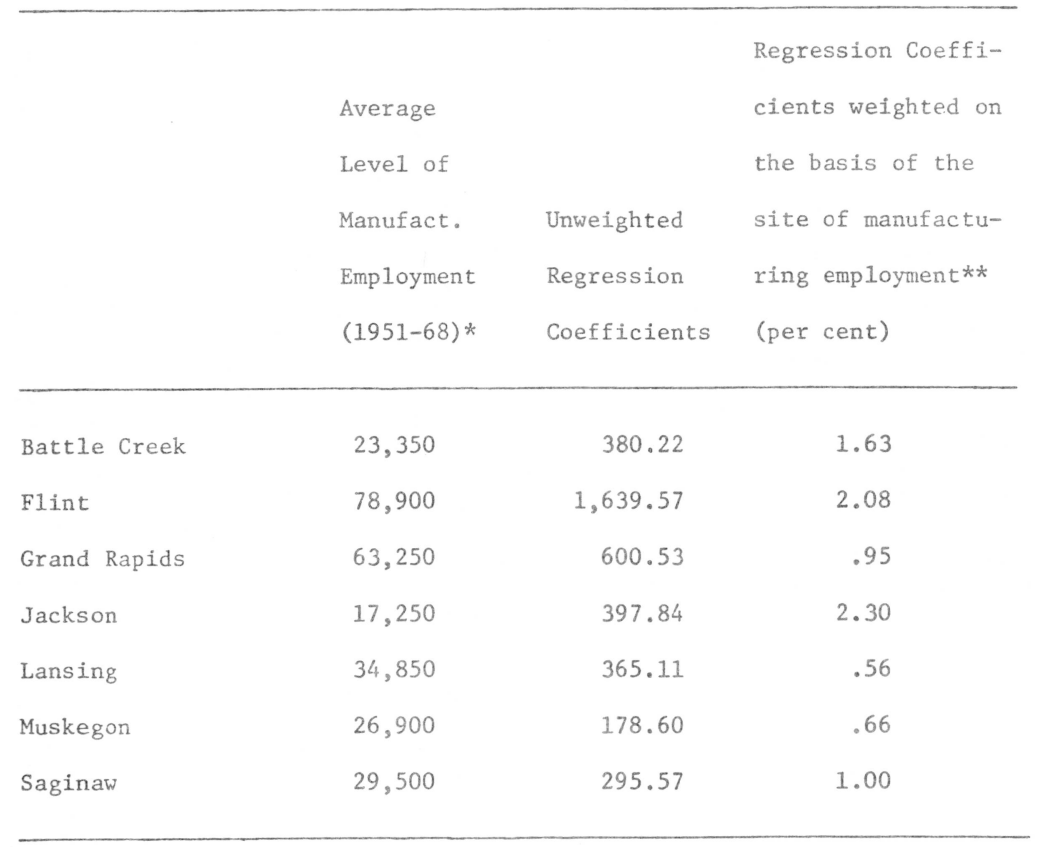

* The average level has been estimated by averaging manufacturing employment at the beginning and end of the period under consideration.

** The weighted regression coefficients were obtained by dividing the coefficients resulting from the regressions by the average level of manufacturing employment in each area. While the unweighted coefficients show the absolute change, the weighted coefficients show the percent change in manufacturing employment resulting from a onehour change in the workweek. 
The correlation coefficients for Benton Harbor show that the basic assumption made in using a distributed-1ag function about the behavior or the regression coefficients over time is not valid in this case, which probably explains why the regression produced a poor fit. 26

The coefficients associated with the lagged value of the dependent variable which is used as an independent variable (i.e. the $\delta$ mentioned in section 3) give an indication of the decrease in the strength of the relationship between the dependent variable. As indicated in table 2, the coefficient varies from a high of approximately thirty-eight percent in Flint to a low of slightly more than twelve percent in Muskegon. It is interesting to note the relative similarity of this coefficient in five of the seven areas that produced significant results.

The intercept $\left(b_{0}\right)$ in the regressions varies in size ans sign according to the area. It is negative in Grand Rapids and positive in all other areas. This constant term can be interpreted as the trend in manufacturing employment, not dependent on the length of the workweek.

\section{Summary and Conclusions}

Certain patterns emerge in the study, despite its aggregate character and various analytical difficulties. The principal finding is the tendency of weekly hours and employment in the manufacturing sectors of most of the nine urban areas to vary together, mainly without a time lag or with a lag of less than four months. The results indicate that employment predictions can be made based on changes in the length of the workweek; the scope for such predictions is rather limited, however, and also depends upon the area involved. Such predictions could be useful to civic groups, various levels of government and other interested parties in their efforts to prevent excessive labor surpluses or shortages by affecting the demand for the products of the different areas (e.g.adjusting the volume of government purchasing of such products), increasing the occupational and spacial mobility of labor or taking other appropriate measures. In this way employment problems could be attacked at the local level where they occur, rather than resorting to general anticyclical policies based on national averages which conceal significant local variations. It should be noted that the results of the study indicate that time lags for employment changes are relatively short; this decreases the usefulness of the analysis for making predictions about employment. A large part of the change in employment does occur simultaneously with the change in hours worked and short time lags (maximum four months) give insufficient time to fully implement policy measures such as those mentioned above.

The paper shows further that time patterns in the relationship between average hours worked and employment in certain areas may be different than those of the nation as a whole. It is particularly interesting to note that the frequently made assumption that changes in the workweek of production workers precedes employment adjustments during both expansions and contractions of demand is not fully supported by the empirical evidence for the areas under consideration. The study suggests that economies which are based on durable goods industries may show different patterns than those based on both durables and non-durables. It also indicates that economies which are characterized by a heavy concentration of durables show a similar patterm in the gradual decrease over time of the effect of a change in hours worked.

There is obviously need for additional research in this direction to find out whether the response of employment to a change in hours worked follows a similar pattern in, other situation (cities of a different size and industry range, for example) or in different parts of the country. 


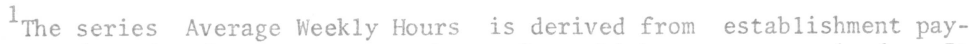
ro11 records and refers to average hours for which pay was received. It differs from Standard or Scheduled Hours as it is affected adversely by such factors as labor turnover, part-time work, absenteeism and stoppages, which are not reflected in the latter series. Variations in the average hours worked are regularly recorded by various agencies and compiled by the Bureau of Labor Statistics of the U.S. Department of Labor.

2 The National Bureau of Economic Research has classified the series Average Weekly Hours as a Leading indicator. See H. M. Willacy, "Changes in Factory Workweek as An Economic Indicator", Monthly Labor Review, October 1970, pp. 25-32. For a discussion of the usefulness of this index in predicting the demand for workers, see A. M. Ross, Techniques for Identifying Labor Shortages and Illustrations of Techniques for Meeting Short-run and Seasonal Labor Shortages. OECD, Social Affairs Division, 1967, Part IV, Pub1ic Labor Market Program.

${ }^{3}$ For an extended discussion of the export orientation of the manufacturing industries of the nine urban areas under consideration, see: G. C. Kottis, Interrelations Among Employment Sectors in Urban Areas: A Time Analysis, Unpublished Ph.D. Dissertation, Wayne State University,June 1970. Chapter III.

4 However, the two kinds of changes do not have to be proportional as firms may be experiencing decreasing or increasing returns.

5 In this paper it is assumed that changes in the labor input which are due to changes in labor productivity or in the relative prices of inputs have mainly long-term effects on employment and do not cause any serious short-term effects on employment and do not cause any serious short-term changes.

${ }^{6}$ For a detailed discussion of the various advantages and disadvantages of short-term fluctuations in the hours worked compared to changes in employment, see A. Bluestone, "Overtime Hours as an Economic Indicator", Monthly Labor Review, September 1956, pp. 1024-1028, and G. Bry, "Why Cyclical Turns in Hours of Work Precede Those in Employment", Employment and Earnings, March 1959 , pp. v-xi.

${ }^{7}$ Overtime premiums have to be weighed against hiring costs (recruitment costs). It is usually thought that hiring costs (plus the fringe benefits given to new workers) exceed the cost of paying overtime, but not everyone agrees with this contention. See J. W. Garbarino, "Fringe Benefits and Overtime Barriers to Expanding Employment", The Industrial and Labor Relations Review, April 1964, pp. 426-442. Furthermore, it has been suggested that overtime premiums may have fallen in the last few years relative to hiring costs. See A. Rees, "Economic Expansion and Persisting Unemployment: An Overview", in R. A. and M. S. Gordon (eds) Prosperity Unemployment, John Wiley and Sons, Inc., New York, 1966, Chapter 8.

${ }^{8}$ R. N. Zeisel, "The Workweek for Production Workers in the Private Economy", Survey of Current Business, September 1969, pp. 21-26.

${ }^{9}$ Willacy Op. Cit., p. 25; G. H. Moore and J. Shiskin, Indicators of Business Expansions and Contractions, National Bureau of Economic Research, New York, 1967.

10 Wetze1, for example, observed that the average weekly overtime hours of factory workers has varied much more in the durable goods than in the 
nondurable goods industries during the period 1956-1966. See J. R. Wetzel, "Current Developments in Factory Overtime", Monthly Report on the Labor Force, U. S. Department of Labor, April 1956, pp. 17-28. In a study of individual plants G. Bry found that cyclical turns in hours of work tend to precede those in employment in most cases, but in many instances they coincide with or even follow those changes. See Bry, op. cit., pp. v-xi.

${ }^{11}$ Thus, a firm run by optimistic managers and using unskilled or lowski11 labor that is available is a well-organized labor market which happens to be free of restrictive union practices may tend to increase employment almost immediately when the demand for its products increases. A firm without these attributes is more likely to adjust first the number of hours worked by its employees, altering employment only after a considerable time lag.

${ }^{12}$ Information was also available for two more urban areas in the same state, namely, Detroit and Bay City. The first area was excluded because of its large size and the second because of its economic and geographic differences from the other areas of the study.

13 The second variable is an index while the first refers to total numbers of employees. The series cover the period between January 1951 and December 1968. The data appear in the following publications of the Michigan Employment Security Commission: Michigan's Labor Market, 1946-64; Michigan

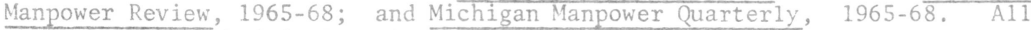
three are published in Detroit.

${ }^{14}$ The deseasonalization was performed using a computer program based on the X-11 Variant of the Census Method II. See The X-11 Variant of the Census Method II Seasonal Adjustment Program, Revised, U. S. Department of Commerce, Bureau of the Census, Technical Paper No. 13, Washington, D.C., February 1967. See also L. Salzman, Computerized Economic Analysis,McGrawHi11, Inc., New York, 1968. Deseasonlization of the time series in question is standard practice for most economic analysis.

${ }^{15}$ See Zeisel op. cit.; Wetzel op. cit., and Employment and Earnings, January 1971, U. S. Department of Labor, chart LL, p. 15.

${ }^{16}$ The maximum number of eighteen monthly lags was chosen tentatively. Addition of more lags would have been possible at any stage if the preliminary results had indicated that the size of the correlation coefficients increased as the lag approached the pre-set maximum of eighteen months.

${ }^{17}$ In a regression equation of that from $x_{t}$ may be highly correlated with $x_{t-1}, x_{t-2}$, and so on.

${ }^{18}$ The complete sequence is as follows:

$$
\begin{aligned}
& \text { (1) } Y_{t}=\beta_{0}+\beta_{1} X_{t}+\beta_{2} X_{t-1}+\beta_{3} X_{t-2}+\ldots . .+\varepsilon_{t} \\
& \text { (1a) } \delta Y_{t-1}=\delta \beta_{0}+\delta \beta_{1} X_{t-1}+\delta \beta_{1} X_{t-2}+\delta \beta_{1} X_{t-3}+\ldots .+\delta \varepsilon_{t-1} \\
& \text { (1b) } Y_{t}-\delta Y_{t-1}=\beta_{0}(1-\delta)+\beta_{1} X_{t}+\left(\varepsilon_{t}-\delta \varepsilon_{t-1}\right) \\
& \text { (2) } Y_{t}=\beta_{0}(1-\delta)+\beta_{1} X_{t}+\delta Y_{t-1}+\left(\varepsilon_{t}-\delta \varepsilon_{t-1}\right)
\end{aligned}
$$

The last coefficient in (1) will be $\beta_{j}$ and on the right-hand side of equation (2) there will be a term $-\delta \beta_{j} X_{t-j}$. In view of the large value of $j$ (eighteen months) and the usually small value of $\delta$, the above term is as- 
sumed to be negligible in magnitude. See J. Johnston, Econometric Methods, McGraw-Hi11, Inc., New York, 1963, pp. 211-221; and E. Malinvaud, Statistical Methods of Econometrics, Rand McNa11y, Inc., Chicago, 1966, pp. 476487. Although the generally held opinion is that $\triangle A H W M$ precedes $\triangle M E$, is true by regressing $X$ on lagged values of $Y$. Lagged employment and current hours correlation coefficients were not always equal to zero but the results were definitely much inferior to those obtained from the relation of $Y$ and lagged values of $X$.

${ }^{19}$ To economize on space, only the ceofficients referring to 1 ags of up to four months appear in the table. In most cases the coefficients for longer lags were non-significant statistically. Those that were significant were isolated cases that did not fit into any pattern. The complete matrix of coefficients and the respective correlograms are available on request.

${ }^{20}$ For an analysis of the industry mix of the nine areas see G.C.Kottis, op. cit., Appendix A. A discussion of the dissimilar behavior of the durable and non-durable goods sectors can be found in Wetzel, op. cit. He suggests that such variations can be due to different cyclical responsiveness, industrial composition, union-management relations and methods of operation.

${ }^{21}$ The staff of the National Bureau of Economic Research has suggested that dissimilar industries can behave differently during the phases of the business cycle; at any given turning point of the cycle one could expect to find some industries in which average weekly hours were rising and some in which they were falling. In combining groups of industries with different time patterns one could get the impression that the two variables expand and contract simultaneously. See Bluestone, op. cit., p. 1027 and W. C. Mitchel1, What Happens During Business Cycles: A Progress Report, Nationa1 Bureau of F.conomic Research, New York, 1951.

$$
{ }^{22} \text { See Bry, op. cit. }
$$

${ }^{23}$ The tabular value of the F-statistic is 3.00 for all the above regressions, while the actual F-values are generally high, the lowest being the one for Saginaw (24.94). On the basis of the F-test two of the nine regressions are not significant statistically; these are Benton Harbor and Kalamazoo. All b-coefficients in the statistically significant seven regressions that appear in table 2 are statistically significant on the basis of the t-test.

${ }^{24}$ It must be noted that the variable $\triangle A H W M$ is an index while the variable $\triangle M E$ has an absolute dimension. If the manufacturing sectors differ in size in the various areas a one-unit change in AHWM will cause a larger change in Me in an area with a large manufacturing sector than in one with a smaller one, other things being equal. By weighing the regression coefficients against the size of the manufacturing sector, a 50-man change in an area with 5,000 manufacturing workers becomes equivalent to a 100-man change in an area with 10,000.

${ }^{25}$ A detailed discussion of various factors affecting the policy of firms concerning length of the workweek and employment can be found in Bry, op. cit., pp. viii-xi. Differences in the behavior of firms can affect the quantitative relationship between the above two variables and cause variation in the value of regression coefficient $b_{1}$. The relationship can also vary over time, (see Willacy, op. cit., pp. 27-30.)

${ }^{26}$ The distributed-1ag function used in the paper assumed that the effect of $\triangle A H W M$ on $\triangle M E$ is stronger when there is no time lag. This condition is violated in Benton Harbor where the effect is stronger when there is a time lag of one month. A modified distributed-lag function for Benton Harbor gave the following equation:

$$
\Delta \mathrm{ME}_{t}=130.00+\underset{(84.343)}{550.840} \Delta \mathrm{AHWM}_{\mathrm{t}-1}+\underset{(0.028)}{0.240} \Delta \mathrm{ME}_{\mathrm{t}-2} \quad \mathrm{R}^{2}=38.0
$$

